\title{
Comparison of idiopathic and secondary uveitis patients seen in a dual pediatric rheumatology- ophthalmology clinic
}

\author{
Victoria TE Rizk*, Mara L Becker, Mark F Hoeltzel, Scott E Olitsky, Andrew Lasky \\ From 2011 Pediatric Rheumatology Symposium sponsored by the American College of Rheumatology \\ Miami, FL, USA. 2-5 June 2011
}

\begin{abstract}
Purpose
Uveitis is an intraocular inflammatory disease that accounts for $10-15 \%$ of all cases of total blindness in the U.S. Although uveitis is more prevalent in adults, children comprise approximately $5 \%$ of the uveitis population. The most common etiologies of childhood uveitis are idiopathic, infectious, and rheumatologic. Idiopathic uveitis is the most common cause of pediatric uveitis, while uveitis associated with Juvenile Idiopathic Arthritis (JIA) is the most common secondary cause. In 2005, the physicians of Children's Mercy's Hospital created a dual Pediatric Rheumatology and Ophthalmology uveitis clinic for patients with ocular inflammation requiring systemic immunosuppressant therapy. An ophthalmologist and rheumatologist jointly evaluate each patient, and formulate a comprehensive plan with the patient and family. To our knowledge, this is the only pediatric uveitis clinic in the U.S. staffed by the two subspecialties simultaneously. The aim of this study was to determine if the characteristics of ocular involvement differ between severe Idiopathic uveitis (IU) and Secondary uveitis (SU).
\end{abstract}

\section{Methods}

A retrospective study of patients identified through a scheduling database that were evaluated in the uveitis clinic from February 2005 to January 2010 was conducted. The patients were subcategorized into two groups: IU and SU based on the association or lack thereof with an underlying autoimmune disease. Clinical characteristics recorded included the involved site of inflammation, laterality, visual acuity, complications defined as ocular structural damage and pressure changes, concomitant number and type of systemic medications needed to control inflammation, and surgical interventions. Frequencies were compared between groups using Chi-square analysis.

\section{Results}

Of the 41 patients seen over 456 encounters, 29 had IU (71\%) and 12 had SU (29\%). Of the 12 SU patients, 10 (83.3\%) had JIA, 6 oligoarticular and 4 polyarticular, 1 (8.3\%) had Sarcoidosis, and 1 (8.3\%) had Hashimoto's. Overall, the maximum number of systemic immunosuppressants used concomitantly was 4 . Throughout the course of treatment, patients received the following medications: methotrexate (95\%), TNF-a inhibitors (34\%), cyclosporine (22\%), and mycophenolate mofitil (15\%). Surgical procedures over the course of follow-up, most commonly vitrectomy and cataract removal, did not differ significantly between groups.

\section{Conclusion}

No statistically significant differences were found in the clinical characteristics and outcomes in patients with IU and SU requiring systemic immunosuppressive therapy. This could be due to a limited sample size, however, these subsets of severe patients may be more phenotypically similar than previously recognized. This may allow for the combination of both subtypes in future studies of childhood uveitis.

\section{Disclosure}

Victoria T. E. Rizk: None; Mara L. Becker: None; Mark F. Hoeltzel: None; Scott E. Olitsky: None; Andrew Lasky: None.

Children's Mercy Hospital, Kansas City, MO, USA

(c) 2012 Rizk et al; licensee BioMed Central Ltd. This is an Open Access article distributed under the terms of the Creative Commons Attribution License (http://creativecommons.org/licenses/by/2.0), which permits unrestricted use, distribution, and reproduction in any medium, provided the original work is properly cited. 
Table 1

\begin{tabular}{llll}
\hline At presentation: & Idiopathic-29 & Secondary-12 & P value \\
\hline Site of involvement & & & $9(75 \%)$ \\
-Chronic anterior & $18(62 \%)$ & $3(25 \%)$ & $0(0 \%)$ \\
-Pars planitis & $7(24 \%)$ & $0(0 \%)$ & 0.76 \\
- Panuveitis & $2(7 \%)$ & $0(0 \%)$ & \\
-Acute anterior & $1(3 \%)$ & & 0.25 \\
-Chronic posterior & $1(3 \%)$ & $10(83 \%)$ & 0.23 \\
\hline Laterality & $19(66 \%)$ & $2(17 \%)$ & 0.23 \\
- Bilateral & $10(34 \%)$ & $2(17 \%)$ & $1(8 \%)$ \\
- Unilateral & $10(36 \%)$ & & 0.77 \\
\hline Visual acuity $>20 / 50$ in worst eye & $7(25 \%)$ & $2(17 \%)$ & 0.63 \\
\hline Visual acuity $>20 / 200$ in worst eye & $1(8 \%)$ & 0.28 \\
\hline Complications & $6(21 \%)$ & $4(33 \%)$ & 0.25 \\
-Synechiae & $4(14 \%)$ & $0(0 \%)$ & \\
-Band keratopathy & $5(18 \%)$ & $3(10 \%)$ & \\
-Ocular hypertension & & \\
-Cataracts & & \\
\hline
\end{tabular}

Published: 13 July 2012

doi:10.1186/1546-0096-10-S1-A80

Cite this article as: Rizk et al:: Comparison of idiopathic and secondary uveitis patients seen in a dual pediatric rheumatology-ophthalmology clinic. Pediatric Rheumatology 2012 10(Suppl 1):A80.

Submit your next manuscript to BioMed Central and take full advantage of:

- Convenient online submission

- Thorough peer review

- No space constraints or color figure charges

- Immediate publication on acceptance

- Inclusion in PubMed, CAS, Scopus and Google Scholar

- Research which is freely available for redistribution

Submit your manuscript at www.biomedcentral.com/submit 